\title{
Evaluation of Sweet Sorghum as a Feedstock by Multiple Harvests for Sustainable Bioenergy Production
}

\author{
Mingli Wang ${ }^{1 *}$, Zhanguo Xin ${ }^{2}$, Brandon Tonnis ${ }^{1}$, Glenn Farrell ${ }^{3}$, David Pinnow ${ }^{1}$, \\ Zhenbang Chen ${ }^{2}$, Jerry Davis ${ }^{4}$, Jianming Yu ${ }^{5}$, Yen-Con Hung ${ }^{3}$, Gary A. Pederson ${ }^{1}$ \\ ${ }^{1}$ USDA-ARS, PGRCU, Griffin, USA \\ ${ }^{2}$ Department of Crop \& Soil Sciences, USDA-ARS, PSGDU, Lubbock, USA \\ ${ }^{3}$ Department of Food Science \& Technology, University of Georgia, Griffin, USA \\ ${ }^{4}$ Department of Experimental Statistics, University of Georgia, Griffin, USA \\ ${ }^{5}$ Department of Agronomy, Kansas State University, Manhattan, USA \\ Email: *mingli.wang@ars.usda.gov
}

Received September 18, 2012; revised October 22, 2012; accepted November 3, 2012

\begin{abstract}
Sweet sorghum has become an important feedstock for bioethanol production. Total sugar yield and multiple harvests can directly affect ethanol production cost. Little is known about stem traits and multiple harvests that contribute to sugar yield in sweet sorghum. Stem traits were evaluated from 25 sweet and grain sorghum accessions. Stems were harvested twice at the soft-dough stage and the stems were pressed with a hydraulic press. Sugars in the stem juice were quantified by high performance liquid chromatography. Sweet sorghum produced five times more fresh stem weight and dry stem mass (830 g and $164 \mathrm{~g}$ ) than grain sorghum (150 g and 27g). Sweet sorghum produced a much higher volume of juice and higher yield of sugars (366 ml and $42 \mathrm{~g}$ ) per stem than grain sorghum $(70 \mathrm{ml}$ and $4 \mathrm{~g})$. Significant variability in fresh stem weight (72 - 1837 g), juice volume (31 - $753 \mathrm{ml}$ ), sugar yield (3 - $81 \mathrm{~g})$, dry stem mass (14 $383 \mathrm{~g})$, and sugar yield/dry stem mass ratio $(0.11-0.53)$ per stem was detected among sweet sorghum accessions. Stem sugar yield was significantly correlated with stem fresh weight and juice volume. Sorghum was harvested twice within one growing season resulting in some sweet sorghum accessions producing double amount of sugars. Sweet sorghum produced three times more dry mass weight (bagasse) than fermentable sugar weight. To reduce feedstock cost, methods have to be developed for efficiently utilizing bagasse. Our results showed high fresh stem weight, high ratio of sugar yield to dry stem mass, and double harvests are prime traits to boost sugar yield. Sweet sorghum may be suitable for multiple harvests in certain regions of the U.S. The U.S. sweet sorghum collection needs to be screened for accessions that can be harvested twice with an extended feedstock-production season and used as a feedstock for sustainable and renewable bioenergy production.
\end{abstract}

Keywords: Sorghum Fresh Stem Weight; Juice Volume; Sugar Yield; Dry Stem Mass; Hydraulic Press (HP); High Performance Liquid Chromatography (HPLC); Multiple Harvest; Bagasse; Sustainable Bioenergy Production

\section{Introduction}

Sorghum [Sorghum bicolor (L.) Moench] is the fifth most important cereal crop in the world, providing human food, animal feed, and raw materials for industrial utilization. Sorghum, cultivated as a major crop, has several unique features: highly efficient- $\mathrm{C}_{4}$ photosynthesis, high wateruse efficiency, and high tolerance to stress (such as drought, salt, high or low temperature, and poor or low soil fertility) $[1,2]$. Due to these unique features, sorghum has emerged as one of the promising feedstocks for sustainable bioenergy production [3-5]. As a bioenergy feedstock, sorghum can be cultivated and utilized in three

${ }^{*}$ Corresponding author. main types: sweet sorghum for sugars, grain sorghum for starch, and biomass sorghum for cellulose. Sweet sorghum is characterized by juicy stems with high amounts of nonstructural carbohydrates (mainly sugars: sucrose, glucose, and fructose) [6]. In comparison with the two other types, sweet sorghum has some obvious advantages. Sugars in the stem juice can be directly used for fermentation to distill ethanol whereas the two other types have to be first converted from cellulose or starch to sugars. Owing to high sugar content in its stems, sweet sorghum in the past has been cultivated for fodder, syrup, molasses, sugars, and small-scale ethanol production [3,7]. For further improvement of sweet sorghum and enhancement of sugar yield, some basic research has been conducted 
on sugar-related traits (different sugar content and sugar ratios, and total sugar yield) and stem traits (fresh weight, juiciness, juice volume, sugar yield, and dry mass). Quantitative trait loci (QTL) for sugar-related traits and stem traits [8-11] were identified and mapped to chromosomal regions. SNP (single nucleotide polymorphism) DNA markers for sweet sorghum were identified and developed by using comparative genomics and microarray technology $[12,13]$. Genetic diversity and population structure of the U.S. historic sweet sorghum collection were also assessed [14,15]. However, the variability in sugar-related traits and stem traits, and the possibility for double (or multiple) harvests have not been evaluated for the U.S. historic sweet sorghum collection. Based on the results of genetic diversity from previous publications [13-15], some sweet and grain sorghum accessions were selected from the U.S. germplasm collection for evaluation of stem traits and multiple harvests. Therefore, the objectives of this study were 1) to determine the variability of fresh stem weight, stem juice volume, stem sugar yield, and dry stem mass in sorghum; 2) to compare stem traits between grain and sweet sorghum; 3) to determine correlations among stem traits; and 4) to determine the suitability of sweet sorghum accessions by multiple harvests for sustainable bioethanol production.

\section{Materials and Methods}

\subsection{Seed Planting and Stem Harvesting}

Sorghum seeds from 25 accessions were requested from two separate locations. Seeds for five grain sorghum accessions and one sweet sorghum cultivar (Rio) were obtained from Dr. Zhanguo Xin, Plant Stress and Germplasm Development Unit, USDA-ARS, Lubbock, TX, USA. Seeds for three grain sorghum accessions and sixteen sweet sorghum accessions were obtained from the Plant Genetic Resources Conservation Unit, USDA-ARS, Griffin, GA, USA (Table S1). Divergent grain and sweet sorghum cultivars were chosen mainly following the published results [13-15]. Ten seeds from each accession were planted in a big pot (Poly-Tainer-Can, No.7s, Nursery Supplies Inc. Orange, CA) containing potting soil (Metromix-360, Griffin House and Nursery Inc., Griffin, GA) in a screen house on May $2^{\text {nd }}, 2011$. Water and fertilizer were well controlled for each pot after planting. Two weeks after germination, seedlings were thinned from ten to four. When the seedlings were well established in the pots they were further thinned from four to three. At the soft-dough stage after flowering, the whole stems were cut above the surface of soil $(1-2 \mathrm{~cm})$ and harvested by removing leaves, sheaths, and panicles. The number of internodes for each stem was counted and the whole stem was weighed. Due to the difference of flowering time among cultivars, the time window for each harvest lasted for about three weeks (from August $1^{\text {st }}$ to August $23^{\text {rd }}$ for the first harvest and from October $27^{\text {th }}$ to November $21^{\text {st }}$ for the second harvest, respectively). The growing period (number of days from planting to the first harvest or from the first harvest to the second harvest) was calculated for each cultivar from each harvest.

\subsection{Stem Juice Content by Hydraulic Press (HP)}

Each weighed-fresh stem was cut into small pieces within one hour. The process for cutting and pressing is illustrated in Figure S1. Nodes (cut with no more than one $\mathrm{cm}$ of internode on each side of the node) and internodes (cut to 5 to $7 \mathrm{~cm}$ long) were collected separately because the hardness and resistance to press from nodes and internodes were different. The inner tissue of all nodes and internodes were exposed by vertically slicing into four sections. Care was taken to prevent any loss of material or juice during preparation. Weight of total nodes and internodes for each stem were recorded separately. A Carver hydraulic press (Model D, Carver Inc., Wabash, IN) with a stainless steel juice press tray was used to collect liquid from the cuttings of nodes or internodes separately. Juice extraction process was achieved by filling up the press cell (up to 500 g) with nodes or internodes and pressed under 34.47 $\mathrm{MPa}$ for $5 \mathrm{~min}$ and then increased to 68.95 and 137.9 MPa for an additional 5 min each using a manual pressure set point controller. A plastic collar shield was placed around the press cell to help collect any liquid coming out from the side of the press cell and direct them into the collecting pan under the press cell. The weight difference before and after press was also recorded. All the juice extracted from each stem was collected in a whirl-bag for sugar analysis. Residual materials (bagasse) from press were collected for determination of dry stem mass.

\subsection{Stem Sugar Content by HPLC Analysis}

Samples of sorghum juice collected from the press were diluted 1:10 with water and filtered (0.45 PVDF filter membrane) prior to injection. Sugar separations were performed using a $7.8 \times 300 \mathrm{~mm}$ resin-based Aminex HPX-87P column (Bio-RAD) on an Agilent 1100 HPLC with a binary pump and refractive index detector (RID). The column and detector temperatures were set at $80^{\circ} \mathrm{C}$ and $50^{\circ} \mathrm{C}$, respectively. A pre-column deashing cartridge (cation $\mathrm{H}^{+}$and anion $\mathrm{CO}_{3}{ }^{-}$) was installed to protect the analytical column. The mobile phase was filtered-sterile water at a flow rate of $0.65 \mathrm{ml} / \mathrm{min}$. Samples were injected at a volume of $10 \mu \mathrm{l}$, and each run lasted $21 \mathrm{~min}-$ utes. Sucrose, glucose, and fructose standards purchased from Sigma were measured, dissolved and diluted in water to the following concentrations (mg/ml): $15,10,5,2$, 
$1,0.5,0.2$, and 0.1 . The diluted sugar samples were used to generate standard curves for peak identification and quantification. Sugar concentration $(\mathrm{mg} / \mathrm{ml})$ determined by HPLC (Figure S2) with juice volume collected from a harvested stem was used to calculate total sugar (g) per stem.

\subsection{Dry Stem Mass}

The moisture content of residual materials from pressing was determined by drying inside a forced-air oven at $80^{\circ} \mathrm{C}$ until there was no more than a $1 \%$ weight change over a $24 \mathrm{~h}$ period. Dry stem mass (g) per stem was determined.

\subsection{Stem Juiciness and Ratio of Sugar Yield/Dry Stem Mass}

Stem juiciness was calculated from juice weight divided by fresh stem weight and expressed as g/g. The ratio of sugar yield/dry mass was calculated from total sugar yield divided by dry stem mass and expressed as g/g.

\subsection{Double Harvest}

After first cutting, ratoon (stubble left after harvesting) of each plant can be developed into new shoots. After a certain period of growth (ranging from August $2^{\text {nd }}$ to November $21^{\text {st }}$ ), these new shoots were developed into new stems but not all the cultivars were suitable for the second harvest. Three criteria used for selection of cultivars suitable for second harvest were: 1) New shoots should not flower too early (vegetative growth $>50$ days); 2) No more than four shoots were developed from each plant (preventing harvesting bushy shoots with more leaf tissue and less stem tissue); and 3) shoots should reach to soft-dough stage at the second harvest before frost. Harvesting after the frost date could significantly reduce soluble sugar content and yield [16]. The cultivars suitable for second harvest are listed in Table S2. For the second harvest, only one stem from each plant and two plants from each cultivar were harvested and further analyzed following the procedure used for the first harvest. The rest of the stems were collected, weighed, and recorded for calculating total fresh stem weight of each cultivar.

\subsection{Statistical Analysis}

Since not all the sorghum cultivars were harvested for the second time, the data from two harvests were analyzed separately. An analysis of variance was performed on the data and means were separated using Tukey's multiple comparison procedure (SAS, 2008, Online Doc ${ }^{\circledR}$ 9.2. Cary, NC: SAS Institute Inc). Significant correlations between stem traits were determined using Pearson correlation coefficients.

\section{Results and Discussion}

\subsection{Double Harvest}

Sorghum may potentially be used as a ratoon crop for multiple harvests to expand the feedstock production season but not all cultivars can be used for a double harvest. After the first cutting, two cultivars (PI 586443 and PI 651493) did not produce any new shoot. Five cultivars (IS3620C, PI 584085, PI 595715, PI 595741, and PI 533998) produced new shoots but were too bushy (without much stem weight) and not suitable for a second harvest. Only cultivars producing two to four stems/per plant were suitable for the second harvest. As demonstrated in Figure S3, cultivars on the top panel were not suitable for the second harvest but cultivars on the bottom panel were. Among 25 cultivars evaluated, only 18 were harvested for the second time (Table S2). Stem traits from the first and second harvest of sweet and grain sorghum are listed in Table S3 and Table S4, respecttively. The growing period was slightly longer in the first harvest (103 days for sweet sorghum and 98.5 days for grain sorghum) than the second harvest (89.3 days and 81.8 days). This difference may be explained by developing root system which needs to be established for the first harvest. There was no significant difference in the internode number of grain sorghum (9.9 and 10.3) between the first and second harvest but there was a significant difference of sweet sorghum (17.1 and 11.2).

For sweet sorghum, there were some differences in the stem sugar concentration between the first and second harvest as shown in Figure 1(a). The concentration of sucrose in the stem from the second harvest $(8.01 \mathrm{mg} / \mathrm{ml})$ was lower (reduced 21\%) than the one from the first harvest $(10.17 \mathrm{mg} / \mathrm{ml})$ whereas the concentration of glucose and fructose in stems was higher from the second harvest $(1.83$ and $1.70 \mathrm{mg} / \mathrm{ml})$ than the one from the first harvest $(0.86$ and $0.63 \mathrm{mg} / \mathrm{ml})$. However, there were two cultivars (PI 217691 and PI 303658) in which the sucrose concentration was not reduced but slightly increased from the second harvest $(10.80$ and $7.85 \mathrm{mg} / \mathrm{ml})$ than from the first harvest $(10.53$ and $6.91 \mathrm{mg} / \mathrm{ml})$. Both of these accessions were originally collected from Sudan and classified into the same genetic cluster of G4/B4 [15]. In a separate study [11], the concentration of sucrose from the second-harvested stem was also measured by a handportable refractometer. In comparison with the results from the first harvest, the brix value (mainly reflecting the sucrose concentration in stems) from the second harvest was reduced $20 \%$. The results for stem sucrose concentration from the second harvests were consistent in these two separate studies.

There were also big differences in other stem traits between the first and second harvest in sweet sorghum as shown in Figure 1(b). Stem weight (830 g), juice volume 


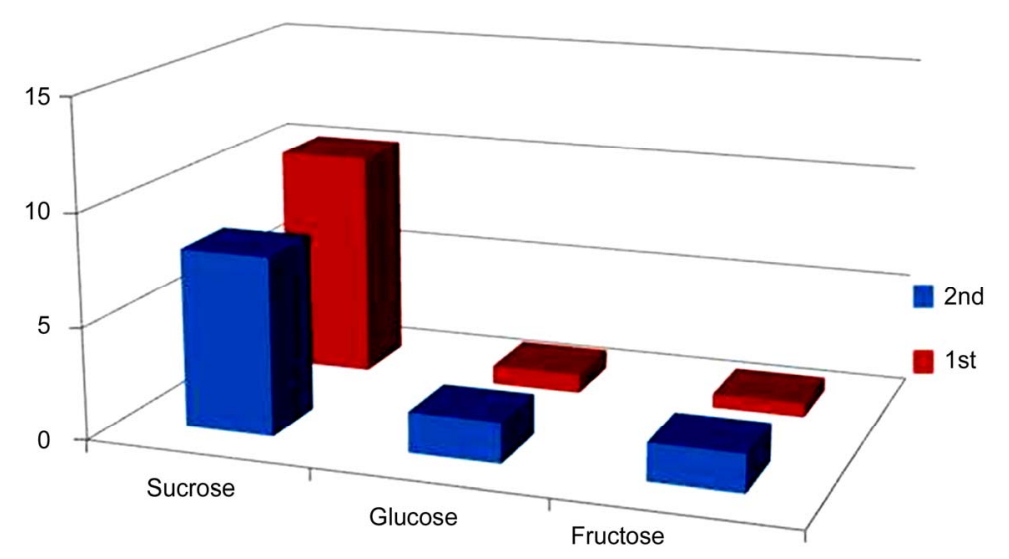

(a)

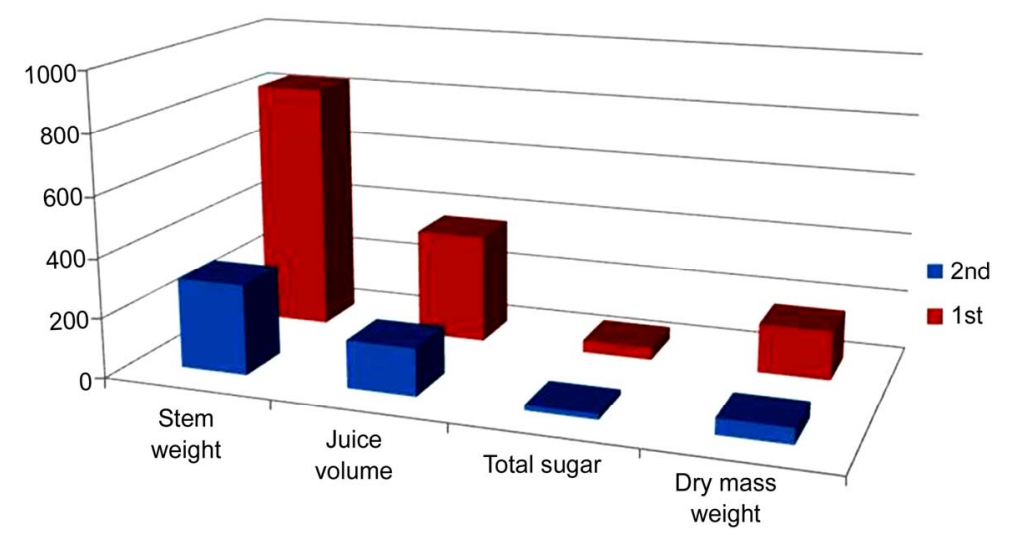

(b)

Figure 1. Comparison of sugar concentration $(\mathrm{mg} / \mathrm{ml})$ and stem characters between the first and second harvest in sweet sorghum. (a) Comparison of sugar concentration between the first and second harvest in sweet sorghum; (b) Comparison of stem characters between the first and second harvest in sweet sorghum.

(365.8 ml), total sugar yield (41.7 g), and dry mass weight (164 g) per stem from the first harvest were much higher than from the second harvest $(301.9 \mathrm{~g}, 158.6 \mathrm{ml}$, $18 \mathrm{~g}$, and $53.1 \mathrm{~g}$, respectively). These differences between the first and second harvest were also consistent with the results from the previous study [11]. However, this significant difference does not necessarily mean all cultivars will produce much higher stem weight and total sugar yield from the first harvest than those from the second harvest because from the first harvest, one plant only produced one stem but from the second harvest, one plant may produce two to four stems. The values of stem traits from the second harvest may need to be multiplied by 2 to 4 and are then used to compare with the values from the first harvest. For example, sweet cultivar Wray (PI 653616) produced $44.69 \mathrm{~g}$ sugar per stem from first harvest and $38.91 \mathrm{~g}$ sugar from the second harvest (Table 1) but there were extra stems collected from the second harvest. This made Wray produce a higher amount of sugar (51.28 g) from the second harvest than from the first harvest (38.91 g) per plant.

\subsection{Comparison of Trait Values between Sweet and Grain Sorghum Cultivars}

There were significant differences in the investigated traits between grain and sweet sorghum cultivars. Significant stem trait variability in sweet and grain sorghum are listed in Table 1 and shown in Figure 2. At the first harvest, on average, sweet sorghum produced significantly higher stem weight (830 g), juice volume (366 ml), total sugar (42 g), and dry mass weight (164 g) than grain sorghum (151 g, $70 \mathrm{ml}, 4 \mathrm{~g}$, and 27 g, Figure 2(a)). This difference may be explained by more nonstructural carbohydrates partitioning to grain filling in the grain sorghum. There was also significant variability in these stem traits from the first harvest among sweet sorghum cultivars. For example, sweet sorghum Grassl (PI 154844) produced $1561 \mathrm{~g}$ stem, $651 \mathrm{ml}$ stem juice, and $329 \mathrm{~g}$ dry mass per stem but sweet sorghum Brawley (PI 533889) produced only $80.5 \mathrm{~g}, 36 \mathrm{ml}$, and $15.5 \mathrm{~g}$. Sweet sorghum cultivar M 81E (PI 653411) produced $70.1 \mathrm{~g}$ total sugar per stem but Brawley produced only 3.1 g total sugar 


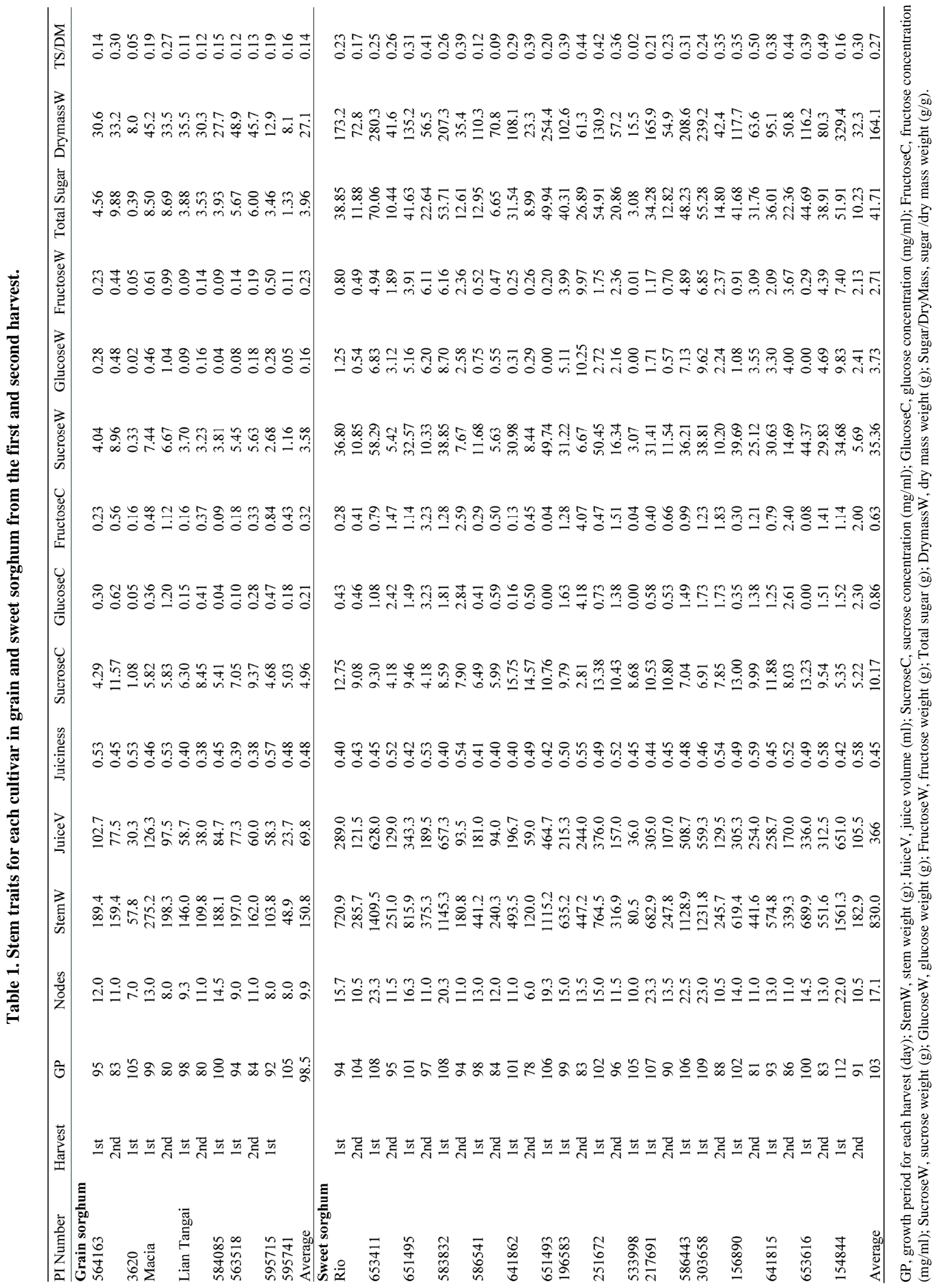




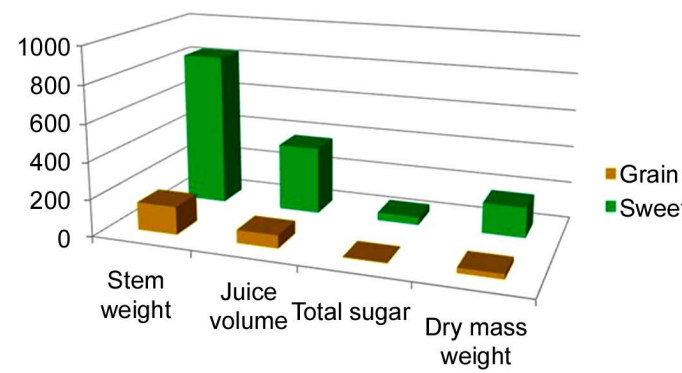

(a)

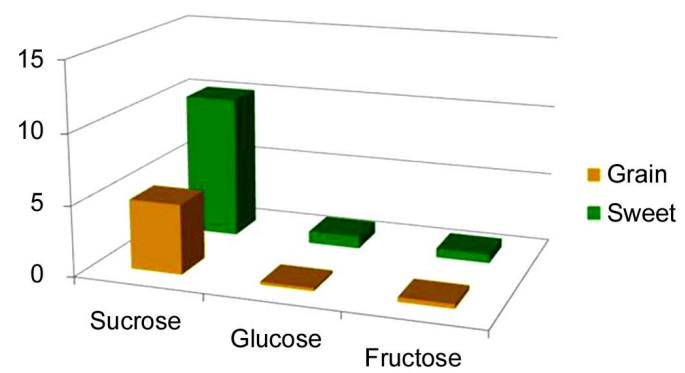

(c)

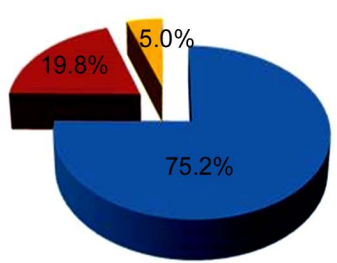

Sweet sorghum

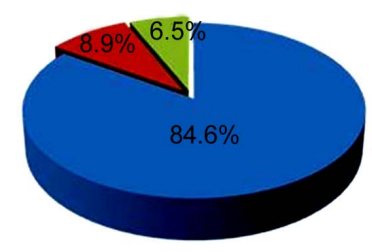

Sweet sorghum

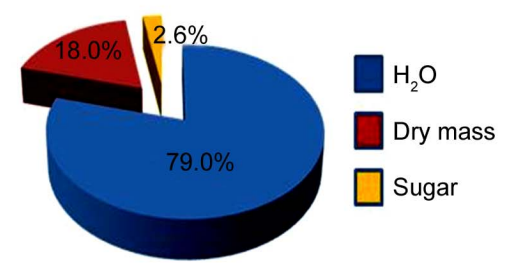

Grain sorghum

(b)

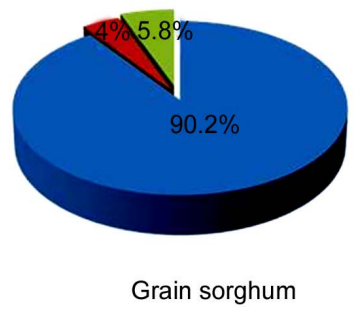

(d)
- Sucrose

- Glucose

Fuctose

Figure 2. Comparison of stem characters, fresh stem composition, sugar concentration (mg/ml), and sugar composition between grain and sweet sorghum. (a) Comparison of stem characters between sweet and grain sorghum; (b) Comparison of the fresh stem composition between sweet and grain sorghum; (c) Comparison of sugar concentration in the fresh stem between sweet and grain sorghum; (d) Comparison of sugar composition in the stem juice between sweet and grain sorghum.

(Table 1 and Figure 2(a)). For the fresh stem composition, sweet sorghum contained a lower amount of water (75.2\%) but a nearly double amount of total sugar (5.0\%) and a higher amount of dry mass (19.8\%) than grain sorghum $(79.0 \%$, 2.6\%, and 18.0\%, Figure 2(b)). In practice, harvested stems need to be transported to bio- refineries for processing [17]. Stems with low water con- tent will make transportation easier with a reduced transportation cost. In sweet sorghum stems, the concentration of sucrose $(10.17 \mathrm{mg} / \mathrm{ml})$, glucose $(0.86 \mathrm{mg} / \mathrm{ml})$, and fructose $(0.63 \mathrm{mg} / \mathrm{ml})$ was much higher than in grain sorghum stem $(4.96 \mathrm{mg} / \mathrm{ml}, 0.21 \mathrm{mg} / \mathrm{ml}$, and $0.32 \mathrm{mg} / \mathrm{ml}$, Figure 2(c)). In comparison of sugar composition, sweet sorghum contained less sucrose (84.6\%), two times the amount of glucose (8.9\%), and a slightly higher amount of fructose (6.5\%) than grain sorghum $(90.2 \%, 4 \%$, and $5.8 \%$, Figure 2(d)). In general, sweet sorghum stem juice contained a high concentration of total sugar and higher proportion of mono-sugars than grain sorghum.

\subsection{Correlations among Stem Traits}

There were twelve traits investigated in this study and their correlations are shown in Table 2 . Stem weight was significantly correlated with juice volume and this correlation was consistent in both sweet sorghum and grain sorghum $(r=0.97$ at $p<0.0001 ; r=0.96$ at $p<0.0001)$. Both stem weight and juice volume were significantly correlated with total sugar yield $(r=0.84$ at $p<0.0001, r$ $=0.89$ at $p<0.0001 ; r=0.8$ at $p<0.0001, r=0.72$ at $p<$
0.0001) whereas the concentrations of sucrose, glucose, and fructose were not highly significantly correlated with total sugar yield except for sucrose concentration in grain sorghum $(r=0.68$ at $p<0.0003)$. These correlations mean selection of high stem weight and high juice volume can effectively enhance total sugar yield in breeding programs. Sucrose weight was significantly correlated with total sugar yield $(r=0.93$ at $p<0.0001 ; r=0.99$ at $p<0.0001$ ). This correlation is not unexpected because sucrose is a major component of the total sugar as shown in Figure 1(a) and Figure 2(c). For the two mono-sugars, glucose weight was highly significantly correlated with fructose weight $(r=0.99$ at $p<0.0001 ; r=0.9$ at $p<$ $0.0001)$. Furthermore, total sugar yield was also significantly correlated with dry mass weight $(r=0.74$ at $p<$ $0.0001 ; r=0.8$ at $p<0.0001$ ). The main target for sweet sorghum breeding orientated for bioethanol production is to increase total sugar yield. As total sugar yield increases, dry mass weight also increases. It is clear that more efficient use of the leftover bagasse after sugar extraction is critical for lowering the feedstock cost as well as the bioethanol production cost.

\subsection{Evaluation of Sweet Sorghum Accessions Suitable for Single or Double Harvest}

Among 17 sweet sorghum cultivars evaluated, the stem of Brawley (PI 533998) contained lowest amounts of sugar (3.1 g) and dry mass (15.5 g). PI 533998 may not be a good accession to cultivate for bioethanol production. 


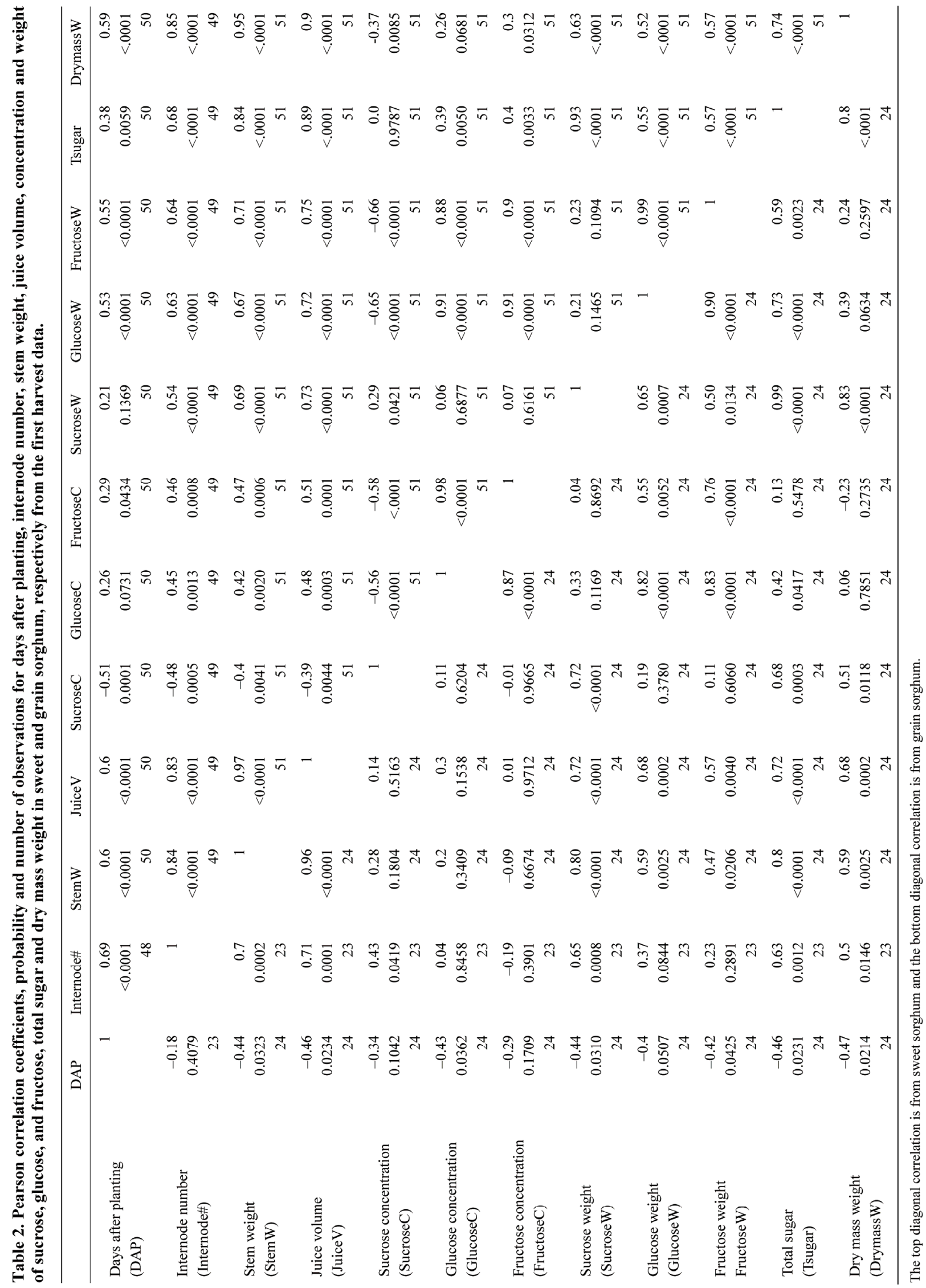


There were five cultivars (PI 653411, PI 583832, PI 251672, PI 303658, and PI 154844) which produced over 50 g sugar per stem from first harvest (Table 1). These may be good candidate cultivars to use for bioethanol production. Among them, PI 251672 and PI 303658 produced a high amount of total stem weight (1183 g and 1164 g, Table S2) with a high amount of sugar yield per stem (20.9 g and $14.8 \mathrm{~g}$ ) from the second harvest. These two cultivars may be considered for a double harvest. Interestingly, we found PI 196583 produced the highest amount of total stem weight (3164 g, Table S2) with a relatively high amount of sugar yield (26.9 g) per stem from the second harvest whereas it only produced $40.3 \mathrm{~g}$ sugar (very close to average $41.7 \mathrm{~g}$ ) per stem from the first harvest. Due to the discrepancy between the two harvests, this cultivar needs to be re-evaluated for determining whether it is suitable for a double harvest.

Sweet sorghum has a long history of cultivation for making sugar-related products, including ethanol. The increased global need to develop sustainable and renewable energy sources from living organisms has attracted more attention to sweet sorghum. Increasing sugar yield and reducing feedstock cost is the main targets for cultivation of sweet sorghum as a sustainable bioenergy feedstock. The preliminary results from our current research demonstrated that total sugar yield from sweet sorghum can be efficiently enhanced by selection of high freshstem weight and high juice volume instead of only increasing sugar concentration in stems. Sweet sorghum cultivars can be harvested twice within the same growing season. Therefore, sugar yield per acreage can be easily increased by double harvesting. Sweet sorghum produces four times the dry mass of sugar weight. To reduce the feedstock cost, a high ratio of sugar yield to dry mass weight has to be integrated into sweet sorghum breeding programs. Sweet sorghum is phylogenetically closely related to sugarcane but their cultivation, suitable growing and harvesting seasons, and adapted-geographic zones may be slightly different. Sugarcane has been successfully used as a feedstock for bioethonal production in Brazil but cannot be harvested throughout the year to supply the feedstock for plant refineries. Sweet sorghum may be used as a perfect complementary feedstock of sugarcane for sustainable and renewable bioethanol production.

\section{Acknowledgements}

The authors thank Drs. Noelle Barkley and Jack Huang for critical reading the manuscript and giving useful suggestions and comments, and to Mr. Brice McEver for technical assistance on harvesting and pressing stems.

\section{REFERENCES}

[1] B. Reddy and P. Redy, "Sweet Sorghum: Characteristics and Potential,” International Sorghum Millets Newsletter, Vol. 44, 2003, pp. 26-28.

[2] S. H. Taylor, S. P. Hulme, M. Rees, B. Ripley, F. I. Wooward and C. P. Osborne, "Ecophysiological Traits in $\mathrm{C}_{3}$ and $\mathrm{C}_{4}$ Grasses: A Phylogenetically Controlled Screening Experiment,” New Phytologist, Vol. 185, No. 3, 2010, pp. 780-791. doi:10.1111/j.1469-8137.2009.03102.x

[3] W. L. Rooney, J. Blumenthal, B. Bean and J. E. Mullet, "Designing Sorghum as a Dedicated Bioenergy Feedstock," Biofuels, Bioproducts and Biorefining, Vol. 1, No. 2, 2007, pp. 147-157. doi:10.1002/bbb.15

[4] M. Calviño and J. Messing, "Sweet Sorghum as a Model System for Bioenergy Crops,” Current Opinion Biotechnology, Vol. 23, No. 3, 2012, pp. 323-329. doi:10.1016/j.copbio.2011.12.002

[5] Z. Xin and M. L. Wang, "Sorghum as a Versatile Feedstock for Bioenergy Production,” Biofuels, Vol. 2, No. 5, 2011, pp. 577-588. doi:10.4155/bfs.11.125

[6] D. M. Vietor and F. R. Miller, “Assimilation, Partitioning, and Nonstructural Carbohydrates in Sweet Compared with Grain Sorghum,” Crop Science, Vol. 30, No. 5, 1990, pp. 1109-1115. doi:10.2135/cropsci1990.0011183X003000050030x

[7] E. Hunter and I. Anderson, "Sweet sorghum," Horticultural Review, Vol. 21, 1997, pp. 40-73.

[8] Y. Bian, Y. Yazaki, M. Inoue and H. Cai, "QTLs for Sugar Content of Stalk in Sweet Sorghum (Sorghum bicolor L. Moench)," Agricultural Sciences of China, Vol. 5, No. 10, 2006, pp. 736-744. doi:10.1016/S1671-2927(06)60118-1

[9] K. B. Ritter, D. R. Jordan, S. C. Chapman, I. D. Godwin, E. S. Mace and C. L. McIntyre, "Identification of QTL for Sugar-Related Traits in a Sweet X Grain Sorghum (So ghum bicolor L. Moench) Recombinant Inbred Population,” Molecular Breeding, Vol. 22, No. 3, 2008, pp. $367-$ 384. doi:10.1007/s11032-008-9182-6

[10] S. C. Murray, A. Sharma, W. L. Rooney, P. E. Klein, J. E. Mullet, S. E. Mitchell and S. Kresovich, "Genetic Improvement of Sorghum as a Biofuel Feedstock: I. QTL for Stem Sugar and Grain Nonstructural Carbohydrates," Crop Science, Vol. 48, No. 1, 2008, pp. 2165-2179. doi:10.2135/cropsci2008.01.0016

[11] S. C. Murray, W. L. Rooney, S. E. Mitchell, A. Sharma, P. E. Klein, J. E. Mullet and S. Kresovich, "Genetic Improvement of Sorghum as a Biofuel Feedstock: II. QTL for Stem and Leaf Structural Carbohydrates,” Crop Science, Vol. 48, No. 6, 2008, pp. 2180-2193. doi:10.2135/cropsci2008.01.0068

[12] M. Calviño, R. Bruggmann and J. Messing, "Screen of Geneslinked to High-Sugar Content in Stems by Comparative Genomics,” Rice, Vol. 1, No. 2, 2008, pp. 166176. doi:10.1007/s12284-008-9012-9

[13] M. Calviño, M. Miclaus, R. Bruggmann and J. Messing, "Molecular Markers for Sweet Sorghum Based on Microarray Expression Data,” Rice, Vol. 2, No. 2, 2009, pp. 129-142. doi:10.1007/s12284-009-9029-8

[14] S. C. Murray, W. L. Rooney, M. T. Hamblin, S. E. Mitchell and S. Kresovich, "Sweet Sorghum Genetic Di- 
versity and Association Mapping for Brix and Height," Plant Genome, Vol. 2, No. 1, 2009, pp. 48-62.

doi:10.3835/plantgenome2008.10.0011

[15] M. L. Wang, C. Zhu, N. A. Barkley, Z. Chen, J. E. Erpelding, S. C. Murray, M. R. Tuinstra, T. Tesso, G. A. Pederson and J. Yu, "Genetic Diversity and Population Structure Analysis of Accessions in the Us Historic Sweet Sorghum Collection,” Theoretical and Applied Genetics, Vol. 120, No. 1, 2009, pp. 13-23. doi:10.1007/s00122-009-1155-6
[16] Y. L. Zhao, Y. Steinberger, M. Shi, L. P. Han and G. H. Xie, "Changes in Stem Composition and Harvested Produce of Sweet Sorghum during the Period from Maturity to a Sequence of Delayed Harvest Dates," Biomass and Bioenergy, Vol. 39, 2012, pp. 261-273.

[17] T. L. Richard, "Challenges in Scaling up Biofuels Infrastructure,” Science, Vol. 329, No. 5993, 2010, pp. 793796. doi:10.1126/science.1189139 


\section{Supplement}

Table S1. Selected grain and sweet sorghum cultivars for first harvest.

\begin{tabular}{|c|c|c|c|c|c|}
\hline PI number & Identifier & Type & Cluster $^{\mathrm{a}}$ & Source & Other Information \\
\hline PI 564163 & ВТх623 & Grain & $\mathrm{n} / \mathrm{a}$ & Xin & Mapping and sequenced line, Texas, United States \\
\hline IS $3620 \mathrm{C}$ & IS $3620 \mathrm{C}$ & Grain & $\mathrm{n} / \mathrm{a}$ & Xin & Mapping parent, Texas, United States \\
\hline Macia & Macia & Grain & $\mathrm{n} / \mathrm{a}$ & Xin & Seed more transparent \\
\hline Lian Tangai & Lian Tangai & Grain & $\mathrm{n} / \mathrm{a}$ & Xin & Cultivar in China \\
\hline PI 584085 & 94USE9327 & Grain & $\mathrm{n} / \mathrm{a}$ & Xin & Uganda \\
\hline PI 563518 & Heilong Sterile \#7B & Grain & $\mathrm{n} / \mathrm{a}$ & PGRCU & Breeding material, China \\
\hline PI 595715 & IS $9738 \mathrm{C}$ & Grain & $\mathrm{n} / \mathrm{a}$ & PGRCU & Conversion breeding material, United States \\
\hline PI 595741 & SC 1063C & Grain & $\mathrm{n} / \mathrm{a}$ & PGRCU & Conversion breeding material, United States \\
\hline Rio & Rio & Sweet & G3/B4 & Xin & Cultivar in United States \\
\hline PI 653411 & M 81E & Sweet & 24/G1/B1 & PGRCU & MER 71-1, Mississippi, United States \\
\hline PI 651495 & Dale & Sweet & 73/G3/B1 & PGRCU & MER 64-12, Mississippi, United States \\
\hline PI 583832 & Top 76-6 & Sweet & 85/G4/B4 & PGRCU & MER 76-6, Georgia, United States \\
\hline PI 586541 & Tracy & Sweet & 10/G1/B1 & PGRCU & BJ-15, Austalia \\
\hline PI 641862 & Collier & Sweet & 13/G1/B1 & PGRCU & MN 715, Mississippi, United States \\
\hline PI 651493 & Ramada & Sweet & 90/G4/B4 & PGRCU & MER 65-2, Mississippi, United States \\
\hline PI 196583 & No.1 & Sweet & 55/G1/B1 & PGRCU & MN 3080, Taiwan, China \\
\hline PI 251672 & 1035 & Sweet & 57/G1/B1 & PGRCU & MN 4135, Yugoslavia \\
\hline PI 533998 & Brawley & Sweet & 71/G1/B1 & PGRCU & NSL 51352, Texas, United States \\
\hline PI 217691 & Nagad el mur & Sweet & 72/G4/B4 & PGRCU & MN 4534, Sudan \\
\hline PI 586443 & IS 27818 & Sweet & 74/G3/B4 & PGRCU & MN 818, Hungary \\
\hline PI 303658 & Nerum boer & Sweet & 77/G4/B4 & PGRCU & MN 4607, Sudan \\
\hline PI 156890 & Dura huria & Sweet & 83/G3/B3 & PGRCU & MN 2462, Zaire \\
\hline PI 641815 & Early folger & Sweet & 86/G1/B1 & PGRCU & MN 9, Mississippi, United States \\
\hline PI 653616 & Wray & Sweet & 91/G1/B3 & PGRCU & MER 69-13, Mississippi, United States \\
\hline PI 154844 & Grassl & Sweet & 95/G4/B4 & PGRCU & MN 1500, Uganda \\
\hline
\end{tabular}

${ }^{\mathrm{a}}$ Genetic cluster from the classification of the U.S. sweet sorghum accessions (Wang et al., 2009). n/a for no data available. 
Table S2. Grain and sweet sorghum cultivars used for the second harvest.

\begin{tabular}{|c|c|c|c|c|c|c|}
\hline PI number & Identifier & Type & Source & $2^{\text {nd }}$ harvest & Growing days $^{\mathrm{a}}$ & Total stem weight (g) \\
\hline PI 564163 & ВТх623 & Grain & Xin & Yes & 83 & 450.4 \\
\hline IS 3620C & IS 3620C & Grain & Xin & No, too bushy & & \\
\hline Macia & Macia & Grain & Xin & Yes & 81 & 681.21 \\
\hline Lian Tangai & Lian Tangai & Grain & Xin & Yes & 81 & 605.23 \\
\hline PI 584085 & 94USE9327 & Grain & Xin & No, too bushy & & \\
\hline PI 563518 & Heilong Sterile \#7B & Grain & PGRCU & Yes & 84 & 658.84 \\
\hline PI 595715 & IS 9738C & Grain & PGRCU & No, too bushy & & \\
\hline PI 595741 & SC $1063 C$ & Grain & PGRCU & No, too bushy & & \\
\hline Rio & Rio & Sweet & Xin & Yes & 104 & 786.6 \\
\hline PI 653411 & M 81E & Sweet & PGRCU & Yes & 95 & 1670.65 \\
\hline PI 651495 & Dale & Sweet & PGRCU & Yes & 97 & 2065.05 \\
\hline PI 583832 & Top 76-6 & Sweet & PGRCU & Yes & 97 & 919.13 \\
\hline PI 586541 & Tracy & Sweet & PGRCU & Yes & 84 & 1190 \\
\hline PI 641862 & Collier & Sweet & PGRCU & Yes & 78 & 1372.1 \\
\hline PI 651493 & Ramada & Sweet & PGRCU & No regeneration & & \\
\hline PI 196583 & No.1 & Sweet & PGRCU & Yes & 83 & 3163.99 \\
\hline PI 251672 & 1035 & Sweet & PGRCU & Yes & 96 & 1183.31 \\
\hline PI 533998 & Brawley & Sweet & PGRCU & No, too bushy & & \\
\hline PI 217691 & Nagad el mur & Sweet & PGRCU & Yes & 90 & 1747.34 \\
\hline PI 586443 & IS 27818 & Sweet & PGRCU & No regeneration & & \\
\hline PI 303658 & Nerum boer & Sweet & PGRCU & Yes & 88 & 1164.11 \\
\hline PI 156890 & Dura huria & Sweet & PGRCU & Yes & 81 & 1465.13 \\
\hline PI 641815 & Early folger & Sweet & PGRCU & Yes & 86 & 1856.38 \\
\hline PI 653616 & Wray & Sweet & PGRCU & Yes & 83 & 1804.93 \\
\hline PI 154844 & Grassl & Sweet & PGRCU & Yes & 91 & 678.81 \\
\hline
\end{tabular}

${ }^{a}$ Growing days were the number of days from the first cut to the second cut. ${ }^{\mathrm{b}}$ Total stem weight was from all the stems at the second harvest. 
Table S3. Variability in stem traits among sweet sorghum cultivars from $1^{\text {st }}$ and $2^{\text {nd }}$ harvest.

\begin{tabular}{|c|c|c|c|c|c|}
\hline Stem trait & Harvest & Mean & Standard deviation & Minimum & Maximum \\
\hline \multirow{2}{*}{ Growing period (days) for each harvest } & $1 \mathrm{st}$ & 103.02 & 5.22 & 93 & 112 \\
\hline & 2nd & 89.29 & 7.17 & 78 & 104 \\
\hline \multirow{2}{*}{ Number of internodes/per stem } & $1 \mathrm{st}$ & 17.06 & 4.52 & 10.00 & 25.00 \\
\hline & 2nd & 11.18 & 1.91 & 6 & 14 \\
\hline \multirow{2}{*}{ Stem weight (g)/per stem } & 1 st & 830.04 & 401.51 & 71.79 & 1837.00 \\
\hline & 2nd & 301.85 & 129.43 & 119.69 & 599.10 \\
\hline \multirow{2}{*}{ Juice volume (ml)/per stem } & $1 \mathrm{st}$ & 365.75 & 170.18 & 31 & 753 \\
\hline & 2nd & 158.64 & 75.98 & 57 & 325 \\
\hline \multirow{2}{*}{ Juice volume/Stem weight (ml/g) } & $1 \mathrm{st}$ & 0.45 & 0.05 & 0.32 & 0.63 \\
\hline & 2nd & 0.52 & 0.06 & 0.40 & 0.65 \\
\hline \multirow{2}{*}{ Sucrose concentration (mg/ml) } & $1 \mathrm{st}$ & 10.17 & 2.95 & 4.83 & 15.91 \\
\hline & 2nd & 8.01 & 3.23 & 2.04 & 15.45 \\
\hline \multirow{2}{*}{ Glucose concentration (mg/ml) } & $1 \mathrm{st}$ & 0.86 & 0.72 & 0 & 2.70 \\
\hline & 2nd & 1.83 & 1.20 & 0.41 & 4.37 \\
\hline \multirow{2}{*}{ Fructose concentration (mg/ml) } & 1st & 0.63 & 0.49 & 0 & 1.65 \\
\hline & 2nd & 1.70 & 1.14 & 0.38 & 4.26 \\
\hline \multirow{2}{*}{ Sucrose weight (g)/per stem } & $1 \mathrm{st}$ & 35.26 & 14.27 & 2.91 & 67.88 \\
\hline & 2nd & 12.29 & 7.78 & 3.15 & 31.16 \\
\hline \multirow{2}{*}{ Glucose weight (g)/per stem } & $1 \mathrm{st}$ & 3.74 & 3.72 & 0 & 11.57 \\
\hline & 2nd & 3.08 & 2.79 & 0.25 & 11.77 \\
\hline \multirow{2}{*}{ Fructose weight (g)/per stem } & $1 \mathrm{st}$ & 2.71 & 2.64 & 0 & 8.19 \\
\hline & 2nd & 2.88 & 2.70 & 0.22 & 11.46 \\
\hline \multirow{2}{*}{ Total sugar (g)/per stem } & $1 \mathrm{st}$ & 41.71 & 16.82 & 2.91 & 81.31 \\
\hline & 2nd & 17.99 & 9.82 & 5.99 & 40.06 \\
\hline \multirow{2}{*}{ Dry mass weight (g)/per stem } & $1 \mathrm{st}$ & 164.11 & 85.76 & 13.90 & 383.25 \\
\hline & 2nd & 53.08 & 19.08 & 18.17 & 94.86 \\
\hline \multirow{2}{*}{ Total sugar/dry mass weight (g/g) } & 1st & 0.28 & 0.10 & 0.11 & 0.53 \\
\hline & 2nd & 0.34 & 0.12 & 0.09 & 0.53 \\
\hline
\end{tabular}


Table S4. Variability in stem traits among grain sorghum cultivars from $1^{\text {st }}$ and $2^{\text {nd }}$ harvest.

\begin{tabular}{|c|c|c|c|c|c|}
\hline Stem trait & Harvest & Mean & Standard deviation & Minimum & Maximum \\
\hline \multirow{2}{*}{ Growing period (days) for each harvest } & $1 \mathrm{st}$ & 98.50 & 4.60 & 92 & 105 \\
\hline & 2nd & 81.75 & 1.91 & 80 & 84 \\
\hline \multirow{2}{*}{ Number of internodes/per stem } & 1st & 9.91 & 2.52 & 7 & 16 \\
\hline & 2nd & 10.25 & 1.49 & 8 & 12 \\
\hline \multirow{2}{*}{ Stem weight (g)/per stem } & $1 \mathrm{st}$ & 150.78 & 76.68 & 43.84 & 296.94 \\
\hline & 2nd & 157.38 & 62.83 & 99.91 & 294.7 \\
\hline \multirow{2}{*}{ Juice volume $(\mathrm{ml}) /$ per stem } & 1 st & 69.83 & 34.65 & 21 & 142 \\
\hline & 2nd & 68.25 & 33.71 & 33 & 137 \\
\hline \multirow{2}{*}{ Juice volume/Stem weight (ml/g) } & $1 \mathrm{st}$ & 0.48 & 0.07 & 0.37 & 0.63 \\
\hline & 2nd & 0.44 & 0.08 & 0.33 & 0.58 \\
\hline \multirow{2}{*}{ Sucrose concentration (mg/ml) } & 1st & 4.96 & 2.46 & 0.89 & 9.99 \\
\hline & 2nd & 8.81 & 2.58 & 3.34 & 11.61 \\
\hline \multirow{2}{*}{ Glucose concentration (mg/ml) } & 1 st & 0.21 & 0.19 & 0 & 0.60 \\
\hline & 2nd & 0.63 & 0.41 & 0.20 & 1.51 \\
\hline \multirow{2}{*}{ Fructose concentration (mg/ml) } & $1 \mathrm{st}$ & 0.32 & 0.29 & 0 & 1.01 \\
\hline & 2nd & 0.60 & 0.38 & 0.30 & 1.39 \\
\hline \multirow{2}{*}{ Sucrose weight (g)/per stem } & $1 \mathrm{st}$ & 3.58 & 2.50 & 0.28 & 9.11 \\
\hline & 2nd & 6.12 & 3.58 & 1.94 & 11.40 \\
\hline \multirow{2}{*}{ Glucose weight (g)/per stem } & $1 \mathrm{st}$ & 0.16 & 0.18 & 0 & 0.68 \\
\hline & 2nd & 0.47 & 0.40 & 0.09 & 1.21 \\
\hline \multirow{2}{*}{ Fructose weight (g)/per stem } & 1 st & 0.23 & 0.22 & 0 & 0.73 \\
\hline & 2nd & 0.44 & 0.37 & 0.13 & 1.16 \\
\hline \multirow{2}{*}{ Total sugar (g)/per stem } & 1 st & 3.96 & 2.74 & 0.33 & 10.53 \\
\hline & 2nd & 7.02 & 4.03 & 2.93 & 13.77 \\
\hline \multirow{2}{*}{ Dry mass weight (g)/per stem } & $1 \mathrm{st}$ & 27.11 & 15.75 & 7.55 & 52.02 \\
\hline & 2nd & 35.68 & 13.25 & 12.16 & 54.91 \\
\hline \multirow{2}{*}{ Total sugar/dry mass weight (g/g) } & $1 \mathrm{st}$ & 0.14 & 0.08 & 0.02 & 0.37 \\
\hline & 2nd & 0.20 & 0.09 & 0.10 & 0.33 \\
\hline
\end{tabular}



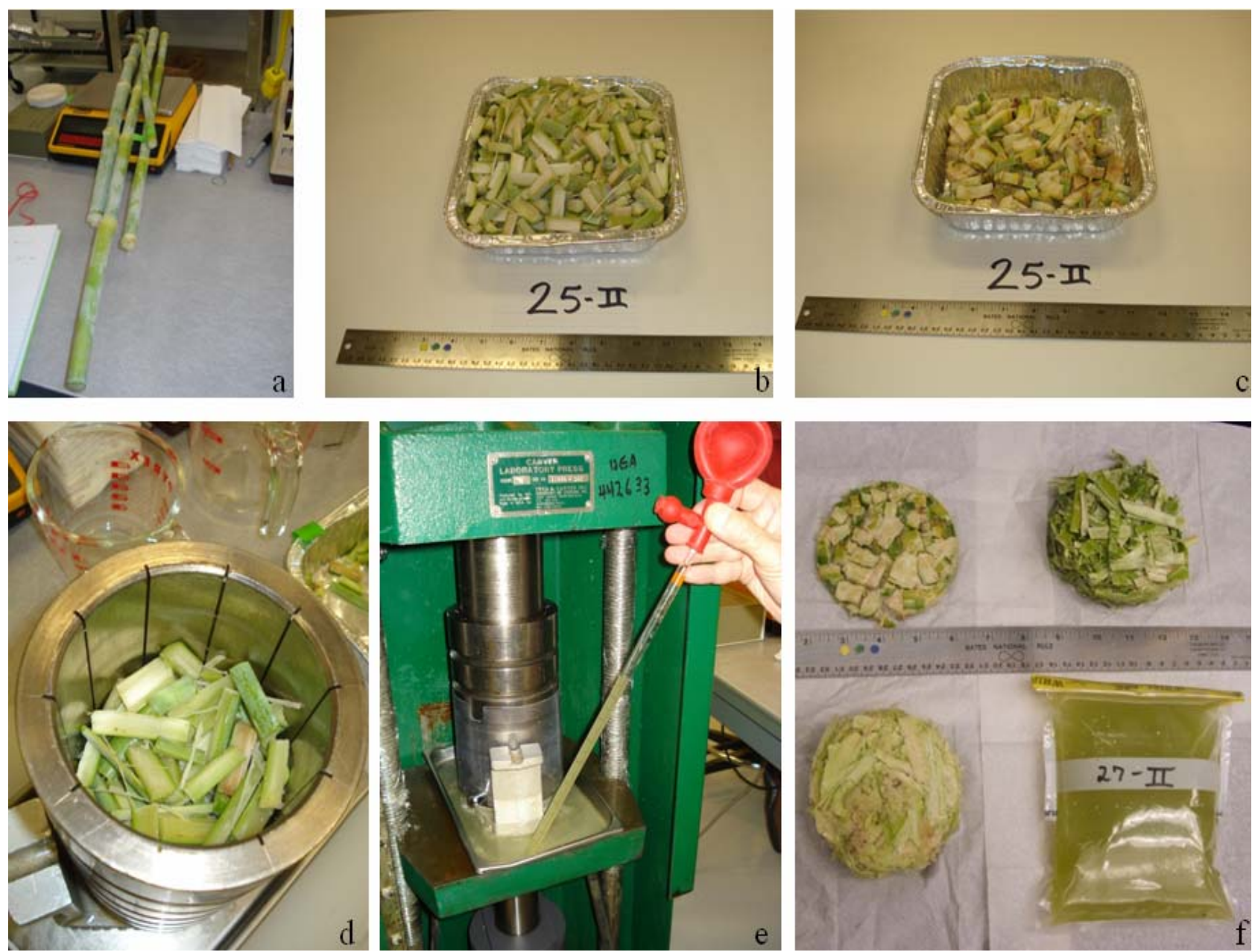

Figure S1. The procedure for collection of stem juice and bagasse from sorghum fresh stems through cutting and pressing. 


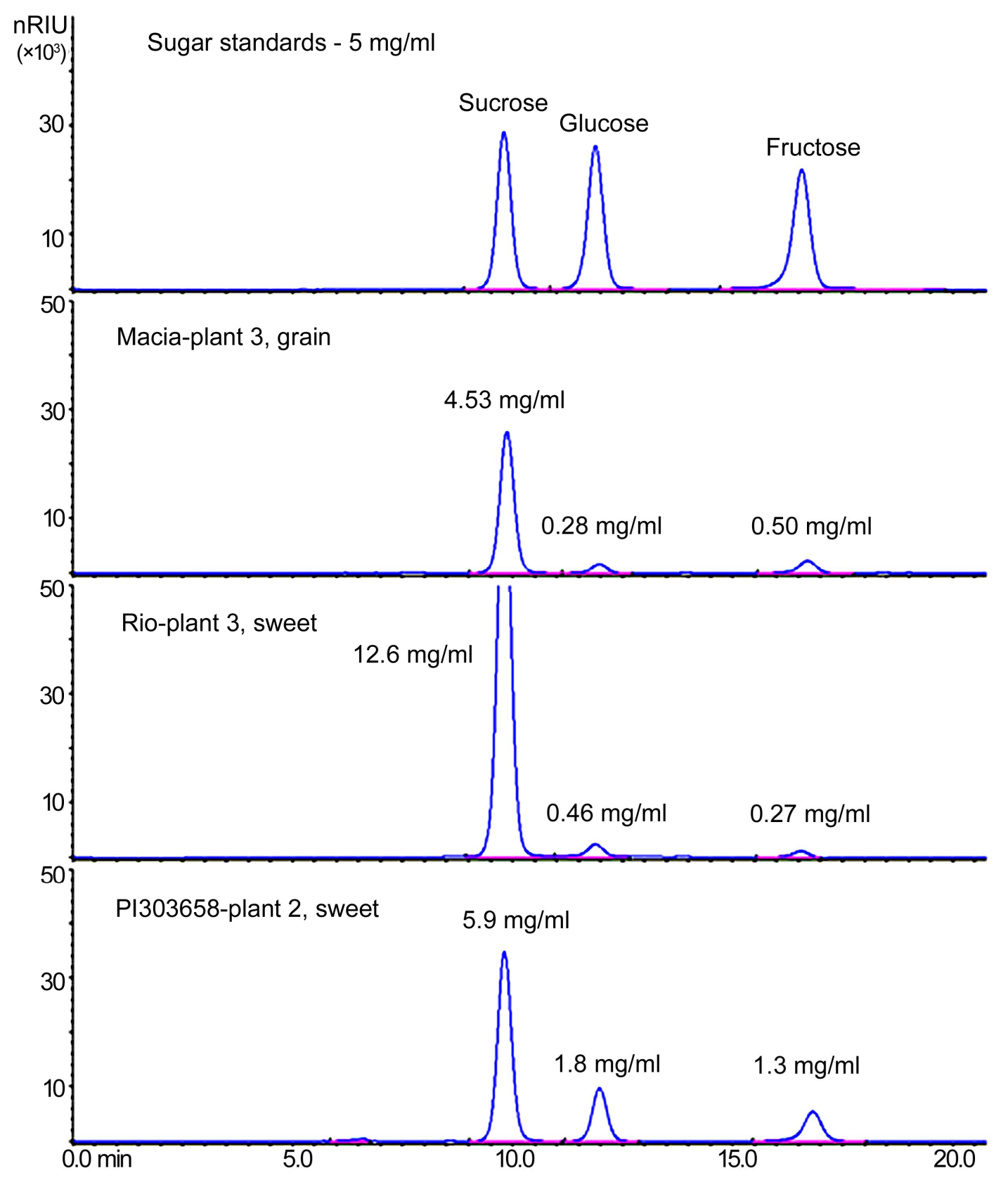

Figure S2. Chromatograms produced by HPLC from sugar standards, grain, and sweet sorghum showing sugar concentration in stem juice. 

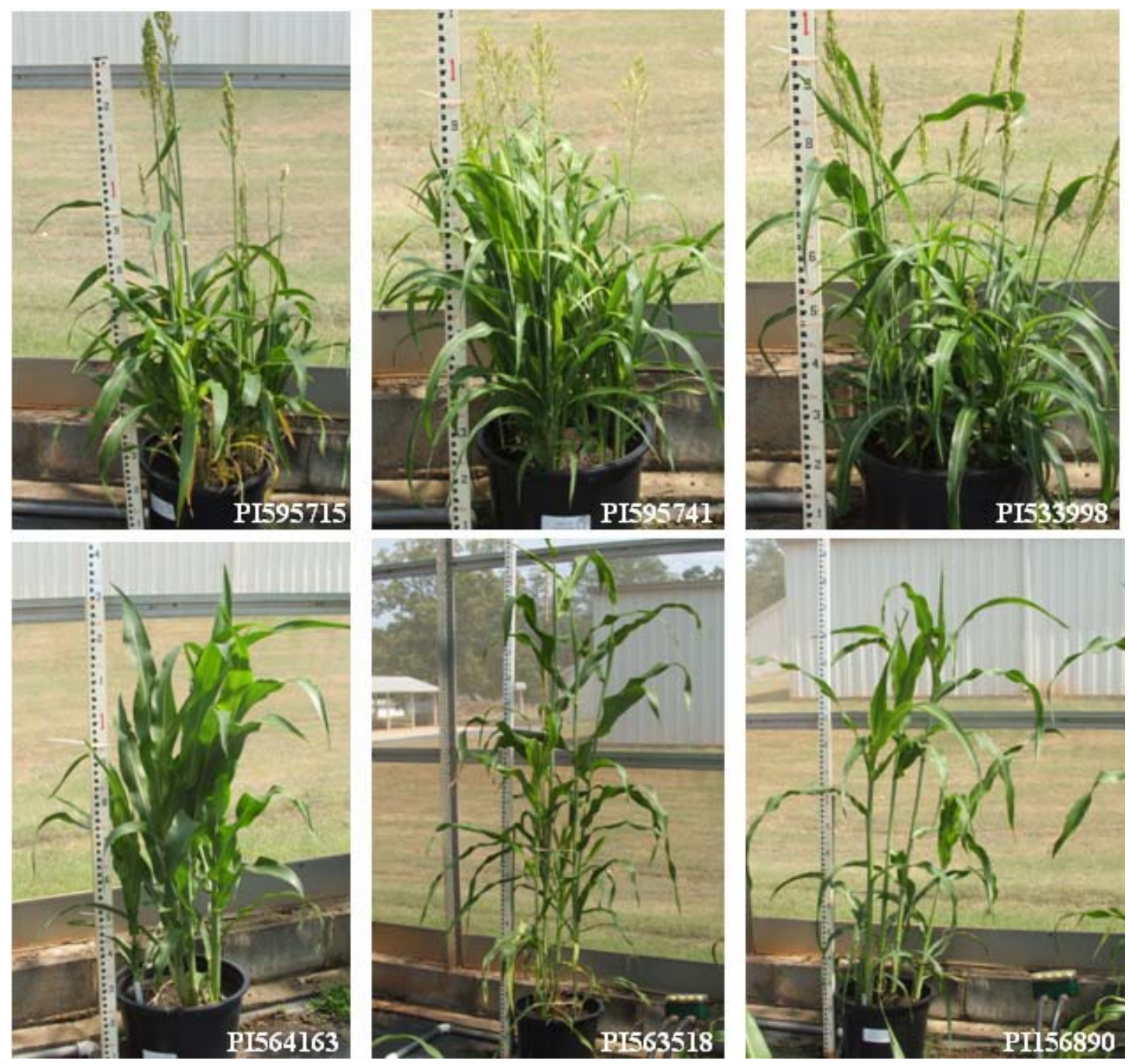

Figure S3. Sorghum plants producing new shoots with a different number of stems after the first cutting. 